\title{
What is Personalized Learning in Secondary Schools?
}

\author{
Pam Epler ${ }^{1}$, Susan Tenon ${ }^{2}$ \\ ${ }^{1}$ Youngstown State University, USA \\ ${ }^{2}$ Fairport Harbor Exempted Village School District, USA
}

\begin{abstract}
This study investigated how Personalized Learning can be incorporated into the studies of students who have an identified special learning need under the Individual with Disabilities Education Act or IDEA in a rural high school in northeastern Ohio, in the United States. The study included $159^{\text {th }}$ thru $12^{\text {th }}$ graders demonstrating their knowledge via an oral presentation using the process of inquiry in a content area which interested them.

Each student presented once during the first and second marking periods and were evaluated by teachers and grade level peers using a 1 - 5 Likert scale on topics such as: content, organization, completeness, quality of documents, use of vocabulary, grammar, timeliness, volume of voice, and interactions with the audience. Results show that the students' scores increased from the first presentation to the second.
\end{abstract}

\section{Introduction}

Personalized Learning or PL, started in the United States back in the 1880's where a school in Colorado determined that each student should learn the classroom content at their own pace. In 1916 Dewey addressed PL by stating that children need to experience their learning not have a teacher stand in front of the class and deliver the information. PL continued to thrive in small sections of the United States until 2014 when school administrators, policy makers and parents decide to adopt this form of education for their schools and attempted to define it [1]. Unfortunately, in 2019, there has not been a consensus about the actual definition of PL nor the components which encompass it [2].

\section{Definition of PL}

According to Gross et al. [2], Personalized Learning has numerous components which include (a) Instruction which will prepare students to be either career, life or college ready through rigorous adherence to state and common core standards. This educational experience must include social and emotional skills to enable students to collaborate with peers, participate as a team member, establish good work ethic skills and obtain the ability to communicate with colleagues. (b) All students must have the opportunity to personalize their learning experience so that they align with their interests. (c) Mastery of content materials must be based on individual student. Learners must be permitted to work at their own pace to either master the academic content quickly or take additional time to learn it. The pace is up to each student. (d) Differentiation of instruction must occur if the student is to graduate within the agreed upon timeline. This instruction must be based on continuous informative assessment and student input. Without this data students will not know what is working well for them. Finally, (e) clear, measurable objectives and long-term goals must be set and reviewed frequently. This will not only assist the student with keeping on track but will also keep the parents informed about how the student is progressing and if they are falling behind.

Pane [3] defines PL in a similar fashion by stating that "The term personalized learning, refers to a diverse variety of educational programs, learning experiences, instructional approaches, and academicsupport strategies that are intended to address the distinct learning needs, interests, aspirations, or cultural backgrounds of individual students. Personalized learning is generally seen as an alternative to so-called "one-size-fits-all" approaches to schooling in which teachers may, for example, provide all students in a given course with the same type of instruction, the same assignments, and the same assessments with little variation or modification from student to student. Personalized learning's general goal is to make individual learning needs the primary consideration in important educational and instructional decisions, rather than what might be preferred, more convenient, or logistically easier for teachers and schools" (p 12).

The United States Department of Education (USDOE) has even defined PL. Under the new Every Student Success Act (ESSA) every student in the United States must be taught with rigorous standards which will prepare them for college or some type of career. The use of PL will assist with accomplishing this goal. Students will be able to demonstrate mastery of academic content not in a traditional classroom seat but in a personalized way. It can be done autonomously on a computer, in a blended classroom whether some of the learning is on line and others are in a face-to-face classroom, or by attending 
community or four-year college classes. The essential component is that the student is engaged in the learning process because it is tailored to their unique needs. This then will lead to improved outcomes, increased productivity, and perhaps even get closer to closing the achievement gap [4].

As noted above, because PL has such broad implications and a wide variety of potential programs and strategies, it may be difficult to determine precisely what the term is referring to when it is used without qualification, specific examples, or additional explanation. Below is the definition of PL for this study.

\subsection{PL definition for study}

For this study, PL, at this particular school, is defined as students having a voice and choice in authentic learning experiences while engaging with the community. In other words, time is flexible. Students may study any of their core classes at any time throughout the school day. Students do not adhere to the traditional school day or calendar. Students have the freedom to create their own personalized learning pathway.

Approximately $1 / 3$ of the high school student enrollment participate in PL as the sole means for earning their high school credits at this rural high school. These 100 students applied to be a part of the personalized learning lab and committed to spend at least part of the day in what the school refers to as the design lab. Parental permission was granted for the students to take part in the personalized learning lab. This design lab is a large open area that includes flexible seating, classrooms with moveable walls, conference rooms, and individual study rooms. There are traditional desk areas, couches, and rolling chairs in addition to large and small tables on which the students may work. The school provides each student with a personal laptop to work on their projects and course work. Email, Google Classroom and other learning management systems (LMS) are the main modes of communication between teachers and students, so technology plays a necessary role in the implementation of this program. In addition to the one-to-one technology available to the students, the school provides for the design lab students' use two 3D printers, a poster maker, desktop computers, and Smartboard technology and white boards for presentations and lessons. Outside-of-school learning experiences are provided and encouraged for all students to participate in addition to spending their time in the design lab. There are five content area teachers available to all students throughout the day: Science, Math, Language Arts, Social Studies and a Special Education/Intervention Specialist. Having all content area teachers present all day long allows the flexibility needed for co-teaching opportunities and cross-curricular projects. Students needing special classes such as physical education, foreign language, or art take those classes in a traditional class setting in the school but outside of the design lab. Speech and occupational therapy services occur in the design lab.
Students in the design lab are assigned to a teacher who mentors and assist them with reminders and extra assistance to complete assignments and checks in with them to ensure they are on track to either complete their work or show adequate progress by the end of the marking period. The student and mentor at the beginning of each marking period conference and develop a Personalized Learning Plan (PLP) which is a working document the student uses to identify their learning style, create both academic and personal goals, track both past and future courses and the progress of completing the courses, and curate artifacts they plan to use in order to show competency in their courses. Specifically, the PLP is the driving tool that the student uses to create the roadmap to personalize their learning experiences. The student's PLP will stay with them throughout their high school career. They will continue to add to the document finetuning goals and learning objectives throughout the years as their learning needs and individual interests change. Throughout the course of the school day, students work individually on their computers, in small groups with their peers or in seminar groups under the direction of a teacher to complete assignments and projects, as well as, conduct research on the topics of interest.

\section{Purpose}

Students with an identified exceptionality already have an IEP, but what if they could take their goals and make them more pertinent to their own interests? This study investigated how Personalized Learning can be incorporated into the studies of students who have an identified special learning need.

\section{Sample}

Of the total number of students currently participating in the PL program, 20 have an identified disability under IDEA. Of those 20, 15 students agreed to participate in this study. Their exceptionalities include Specific Learning Disability (SLD), Autism Spectrum Disorder (ASD), and Intellectual Disability (ID).

\section{Methodology}

A quantitative methodology with a CausalComparative design was used to compare the oral presentations from the first marking period to the second.

\section{Research Question}

Is there a difference (in content, organization, completeness, quality of documents, use of vocabulary, grammar, timeliness and mannerisms/interactions with the audience) between the beginning and the middle-of-the-year presentations of 15 rural, northeastern Ohio 9 th $-12^{\text {th }}$ 
students with an exceptionality who are accessing and showing competency of the state standards using PL?

\section{Student Presentations}

The 15 students with an identified disability consulted with the content area teacher who aligned with their topic. This was an important step because it was critical that the student not only found a topic of interest to them, but that it was inquiry-based topic, meaning the students need to pose a question or problem and then investigate the question or problem to arrive at some sort of conclusion. The teacher and students were able to arrive accomplish this through the creative process of brainstorming and pitching their ideas to classmates. Once the teacher approved the topic, the student researched the topic and created a proposal of how they were going to accomplish their goals specifically which resources would they need to use and what information they needed to gather. After the information gathering, students put together a PowerPoint and practiced explaining their project. Students consulted teachers as needed throughout the process, and teachers conducted small group checkins to ensure the students were moving in the right direction, address any challenges the students were facing, brainstorm solutions and make sure students were on track to complete the project prior to the deadline. In addition to the small group check-ins, a Google form was created for students to use as needed if they had any specific questions for a specific teacher. This was another support and a way the teachers and students created a culture that learning happens anytime and anywhere. Prior to the presentations, students worked with individual content area teachers to identify the specific standards they would be addressing during their presentations. The students presented their project over several days during the first and second nine week marking periods.

On the day of the presentation before the students arrived that morning, the teachers randomized the order of student presentations, so the students did not know where they fell in the presentation order. It was important to the teachers that these presentations not only assessed content knowledge that was mastered but also those employability skills such as meeting deadlines and punctuality that are sometimes difficult to assess in a more traditional classroom. Because the presentation order was randomized and not announced until the morning of the first presentation, all students needed to be ready to present on the first day. It was a way to level the playing field.

For the project presentations, students presented a PowerPoint of their findings for five to eight minutes and were asked questions afterwards. During the demonstration, three teachers and three fellow students evaluated each presentation. The student and adult evaluators provided a minimum of one written positive common and noted one area or suggestion for improvement on the rubric in the comments section. Both student and adult evaluators provided verbal feedback to the presenter immediately following the presentations. This unstructured time allowed the audience to ask questions, provide suggestions for future presentations, and note areas of strength. Both student presenters and student evaluators benefited from this interaction because the student evaluators were able to overcome some challenges in their own presentations before making their presentation. The teachers and student evaluators varied throughout the day depending on schedules. In addition to making their own presentation, all students had to evaluate a minimum of three other presentations. Following the presentations, all students were able to access their individual rubric results with feedback. Students and adults evaluated the presenter using a rubric that included the following areas: content, organization, presentation completeness, documents and graphics, use of vocabulary, grammar, timeliness, mannerisms, and interactions with the audience. They used a Likert scale with $1=$ lowest and $4=$ highest score.

For the purpose of this study, content is defined as the relevance of the topic, the accuracy of the information presented, and if the presentation is tightly focused (i.e. does not drift from the inquiry question). Evaluators were looking at the overall treatment of the topic. The organization section of the rubric assesses the logical order of ideas including an engaging introduction or engaging the audience with a story, a fully developed body portion of the presentation, and conclusion requiring transitions between major points. Evaluators examine the order of ideas and make sure the presentation is clear and concise. Completeness assesses the level of detail provided and that the presentation is neither too long nor too short. Evaluators determine if there is adequate background provided so any audience member can understand the topic regardless if they are familiar with it or not. The documents section is defined to include graphs, clip art, pictures, and background. Specifically, evaluators are looking for not only the overall accuracy of the document but the aesthetics as well. Was there care taken when putting together the presentation? The use of vocabulary requires that all terms are used and pronounced correctly. Evaluators examine the number of terms the student uses and if they are used correctly. The grammar section requires the presentation to be free of errors, jargon, and easy to understand. Grammar includes both punctuation and style. Timeliness assesses if the students are prepared to present on the exact time and date they are called to present. Mannerisms include both the volume and pace of the speaker's presentation as well as avoiding distracting gestures. Evaluators examine the professional appearance of the presenter and assess if the visual aids are used effectively. The interactions with the audience section of the rubric evaluates appropriate eye contact and engagement with the audience, as well as, the ability to listen and answer audience questions with accuracy and authority. Evaluators assess the overall rapport the presenter develops with the audience.

During the second evaluation, the teacher and student assessors were given a blank evaluation form 
for each student. The evaluators used the same criteria for both the first and second presentations. The first presentation scores were not provided.

\section{Data Analysis}

Once the presentations were completed, the evaluations were collected. Each was reviewed to ensure all entries were completed. Once this task was completed all of the data was entered into an Excel spreadsheet and entered into SPSS. An independent ttest was then run.

\section{Results}

Numerous students did earn a high score of a 4 during the first presentation in timeliness, a 3.6 in Content, a 3.34 in organizational clarity, a 3.3 in completeness, a 3.4 in documents, a 3.4 in the use of vocabulary, a 3.3 in grammar, a 3 in volume, and a3.34 in interaction. During the second presentation, they also scored a 4 during in timeliness, a 3.6 in content, a 4 in organizational clarity, a 3.6 in completeness, a 4 in documents, a 4 in the use of vocabulary, a 4 in grammar, a 3.34 in volume, and a 3.67 in interaction.

Several students did earn a score of 1 on the first evaluation in grammar and three students earned a 1 on the second evaluation in grammar, volume of voice and interaction with the audience.

The results indicate that there was an increase from the first presentation to the second in all of the evaluated areas. In content, the scores rose from 2 to 3.67 (54\% difference), organization rose from 1.3 to 2.34 (43\% difference) completeness rose from 1.3 to 3.34 (39\% difference), documents rose from 1.6 to 4 (40\% difference), use of vocabulary rose from 1.6 to 3.67 (44\% difference), grammar rose from 1 to $4(25 \%$ difference), timeliness rose from 2.6 to $4(65 \%$ difference), volume of voice, rose from 1.3 to 3.67 (35\% difference) and interactions with the audience rose from 1.6 to 3.34 (48\% difference).

\subsection{Discussion of Results}

As shown by the data above, students with an identified exceptionality improved on their presentations from the beginning of the year to the middle of the year. Some of the improvements were larger than others with the biggest gain being in the area of timeliness and the lowest being in the area of grammar. Having this knowledge, both the student and the teacher who is working with them can take this data and make improvements so that the next time the student presents his or her scores will be even higher.

\section{Recommendations}

The following recommendations are made for this study. (a) This study was conducted in a small rural high school. It is recommended that it be replicated in a larger urban or even suburban high school. (b)There are four nine-week marking periods during the school year. It is recommended that the student conduct their presentations during each marking period so they can see improvements throughout the school year. (c) This study was conducted with a small sample. It is recommended that a larger one be used. Finally, (d) this study was completed with only students with identified special needs under IDEA. The study should be replicated with students with non-disabled students.

\section{References}

[1] Dockterman, D. (2018). Insights from 200+ years of personalized learning. Science of Learning 3(15), 1-6. doi:10.1038/s41539-018-0033-x Retrieved from: https://www.nature.com/articles/s41539-018-0033x.pdf?origin=ppub

[2] Gross, B., Tuchman, S., \& Patrick, S. (2018). A national landscape scan of personalized learning in K-12 education in the United States. iNACOL, Vienna, VA.

[3] Pane, J.F. (2018). Strategies for implementing personalized learning while evidence and resources are underdeveloped. Perspective, Document Number: PE-314R. Rand Corporation, p. 12. www. rand.org. DOI: https://doi.org/10.7249/PE314

[4] United States Department of Education (n.d). Competency-based learning or personalized learning. Retrieved from https://www.ed.gov/oii-news/competencybased-learning-or-personalized-learning 